\title{
Self-esteem, willingness to communicate, and oral production: The case study of Iranian intermediate EFL students
}

\author{
Mohadese Habib zade ${ }^{1}$, Akram Hashemi ${ }^{2, *}$ \\ ${ }^{1}$ MA Candidate of Islamic Azad University, Roudehen Branch, Iran: Faculty of foreign languages and Persian Literature \\ ${ }^{2}$ Assistant professor of Islamic Azad University, Roudehen Branch, Iran: Faculty of foreign languages and Persian Literature
}

Email address:

Mohades60@yahoo.com (M. H. zade), akram.hashemi2013@gmail.com (A. Hashemi)

To cite this article:

Mohadese Habib zade, Akram Hashemi. Self-Esteem, Willingness to Communicate, and Oral Production: The Case Study of Iranian Intermediate EFL Students. International Journal of Language and Linguistics. Vol. 2, No. 4, 2014, pp. 290-294.

doi: $10.11648 /$ j.ijl1.20140204.17

\begin{abstract}
Oral production in general and lecturing in particular plays a significant part in any academic field, especially in TEFL. This study aimed to illuminate and investigate the two psychological and crucial factors influencing the oral production: Willingness to Communicate (WTC) and Self-Esteem. An attempt was made to assess the relationship among WTC, Self-Esteem, and Oral production. In so doing, after homogenizing the students as Intermediate ones via a placement test, two questionnaires of WTC (McCroskey, 1987, 1992) and Self-esteem ( Sorensen, 2006) were administered to 34 intermediate students. Having administered the questionnaires, the researcher asked the subjects to deliver a lecture on general and controversial topics. Based on the questionnaires, the subjects were divided into four groups: 1) High WTC, High self-esteem, 2) High WTC, Low self-esteem, 3) Low WTC, High self-esteem, and 4) Low WTC, Low self-esteem. The data collected from the questionnaires as well as the scores given to their oral productions were analyzed through SPSS (16.00). Results indicated statistically significant differences between the two groups of High WTC, High Self-esteem and Low WTC, Low Self-esteem. The former group outperformed the latter one. The outcomes of this study could have benefits for both foreign language teachers and learners. They both can attain better results by focusing more on these two psychological factors in their roles. The findings of the present study demonstrated that more concentration ought to be placed on these two psychological factors in order to enhance students' oral performances.
\end{abstract}

Keywords: Oral Production, Self-Esteem, Willingness to Communicate

\section{Introduction}

Human beings live with different important characteristics. One of the main characteristics of human beings is the view they have of themselves technically referred to as self-esteem. Self-esteem has recently become a hot topic for research in education and language teaching and refers to the image and view people have of themselves. The assessment and evaluation of a person's emotion concerning his worth is self-esteem. Self-esteem is considered as an evaluative component of the self-concept (Purkey, 1970) through which people evaluate themselves based on the feedback from others. Marsh (1990) who believes in academic achievement contends that self-esteem is an important factor in social construct and psychological view.
One more psychological construct gaining recognition in the last decade is Willingness to Communicate (WTC) in humans. Initially introduced by MacIntyre, Clement, Dornyei, and Noels (1998) for language studies, WTC can function as both an individual difference variable in learning L2 in addition to its being a goal for L2 instruction. Both WTC and self-esteem have been less researched in the Iranian EFL context when compared with other individual factors such as motivation, aptitude, and learning strategy. This gap in the literature is more evident when it comes to the potential effect WTC and self-esteem can have on oral production in L2 acquisition. This study was after the investigation of the prospective relationship between these two individual variables (WTC and self-esteem) and oral production in Iranian English language learners.

Learning can be accelerated in a more psychologically 
friendly environment. Two of the psychological factors assumed to be influential in L2 learning are self-esteem and Willingness to Communicate. These two factors are very helpful in learning a new language. Both self-esteem and WTC are conducive to better language learning opportunities. In the Iranian language learning atmospheres, teachers and learners seem to be less aware of the constructive effect of these two psychological factors. As Bachman and Palmer (1996) believe, self-esteem is the first and main factor in speaking performance. In addition, Chan and McCroskey (1987) claim that students with higher scores on the WTC scale are more likely to have more oral production in class than those who scored low on WTC. Yashima, Zenuk-Nishide and Shimizu (2004) also claim that students who show willingness to communicate in various contact situations are more inclined to initiate communication in the classroom. Therefore, teachers should be informed about the importance of these two variables especially when it comes to production skills which require more self-esteem and WTC.

This study had two main purposes. The first purpose of this study was to investigate the relationship between Iranian English language learners' level of self-esteem and their oral production in their lectures in the classes. The second purpose of this study was to explore the level of Willingness to Communicate (WTC) among these English language learners to see if there was any significant relation with their oral production skills and WTC in their class lectures.

\subsection{Research Questions and Hypotheses}

Q1: Is there any significant relationship between Intermediate EFL students' level of self-esteem and their oral production?

Q2: Is there any significant relationship between Intermediate EFL students' level of WTC and their oral production?

Q3: Is there any significant relationship between the interactional effect of Intermediate EFL students' selfesteem and WTC with their oral production?

Null H1) There is not a significant relationship between intermediate EFL students' Self-esteem and their oral production.

Null H2) There is not a significant relationship between intermediate EFL students' WTC and their oral production.

Null H3) There is not a significant relationship between oral production of intermediate EFL students and the interaction of self-esteem and WTC.

\subsection{Participants}

The participants were 45 MA English language students (male and female) of EFL students at Islamic Azad University of Zanjan and were randomly selected from the classes available. From among these 45 participants, the ones belonging to the Intermediate group (34 students) were selected based on their proficiency test. Their age ranged between 20 and 45 .

\section{Design, Procedure, and Instruments}

The design of this study was factorial design since there were two independent variables (self-esteem \& WTC) and one dependent one (oral production). In the first two questions, the main effects of self-esteem and WTC on oral production were accounted for respectively. In the third question, the interactional effect of both independent variables on oral production was taken into considerations.

In order to guarantee the homogeneity of the subjects of this study and to fulfill the objectives of the study; first, a standard Cambridge placement test was distributed among the all 45 students to determine their level of proficiency. Thirty four students who were ranked as intermediate were selected to participate in this research. Then a standard selfesteem questionnaire (Sorensen, 2006) was distributed among all students to achieve their general self-esteem (global self-esteem). Another questionnaire of WTC (McCroskey, 1987, 1992) was also administered to the same subjects. Afterwards, two general and controversial topics were introduced to the students and they were asked to give a short lecture on them. Two raters were later asked to score their speaking performances on the basis of the rubric introduced by Farhady et.al. (1998). By turn, students presented a lecture on two different general topics while they were allowed to choose either one according to their interest and favor. All performances were videorecorded and then two university professors as raters were asked to evaluate and score them. Rating scales were based on Farhady et al. (1999). This classification which covered pronunciation, vocabulary, grammar, fluency, and comprehension with the rank scale from 1 to 6 for each trait was the main criteria in this study.

Based on the collected data, four groups were formed:

1. High WTC - high self-esteem group

2. High WTC- low self-esteem group

3. Low WTC - low self-esteem group

4. Low WTC - high self-esteem group

A one-way ANOVA was run to compare the means of the groups on the proficiency test in order to prove that they enjoyed the same level of general language proficiency prior to the main study. Furthermore, in order to measure the relationship between the variables (self-esteem $\&$ oral production) and (WTC \& oral production), two Pearson Correlation tests were administered. . In addition, a oneway ANOVA was run to compare the four groups' means on the lecturing test. Besides, in order to account for the interactional effect of WTC and self-esteem on lecturing, a Post-Hoc Scheffe's Test was administered. Later, again a Pearson Correlation test was run to measure the Inter-Rater Reliability.

\section{Data Analysis}

A one-way ANOVA was run to compare the means of the groups on the proficiency test in order to prove that they enjoyed the same level of general language proficiency 
prior to the main study. Based on the results displayed in Table $1\left(\mathrm{~F}(3,31)=.40, \mathrm{P}>.05 ; \omega^{2}=.053\right.$ it represents a weak effect size) it can be concluded that there were not any significant differences between means of the four groups on the proficiency test. Thus it can be claimed that they enjoyed the same level of general language proficiency prior to the main study.

Table 1. One-Way ANOVA Proficiency by Groups

\begin{tabular}{llllll}
\hline & Sum of Squares & Df & Mean Square & F & Sig. \\
\hline $\begin{array}{l}\text { Between } \\
\text { Groups }\end{array}$ & 123.500 & 3 & 41.167 & .400 & .754 \\
$\begin{array}{l}\text { Within } \\
\text { Groups }\end{array}$ & 3290.722 & 30 & 102.835 & & \\
Total & 3414.222 & 33 & & & \\
\hline
\end{tabular}

\section{Inter-Rater Reliability}

A Pearson correlation was run to probe the inter-rater reliability of the two raters who rated the subjects' oral production. Based on the results displayed in Table 2 ( $\mathrm{r}$ (32) $=.79, \mathrm{P}<.05$ representing a large effect size) it can be concluded that there was a significant agreement between the two raters:

Table 2. Pearson Correlation; Inter-Rater Reliability

\begin{tabular}{lll}
\hline & Rater2 \\
\hline \multirow{3}{*}{ Rater1 } & Pearson Correlation & $.794^{* *}$ \\
& Sig. (2-tailed) & .000 \\
& $\mathrm{~N}$ & 34 \\
\hline
\end{tabular}

**. Correlation is significant at the 0.01 level (2-tailed).

The three null hypotheses are brought and evaluated as follows:

Null H1) There is not a significant relationship between intermediate EFL students' Self-esteem and their oral production.

A Pearson correlation was run to probe any significant relationship between Intermediate EFL students' level of self-esteem and their oral production. Based on the results displayed in Table 3 ( $\mathrm{r}(32)=.72, \mathrm{P}<.05$ representing a large effect size) it can be concluded that there was a significant and large correlation between self-esteem and oral production. Thus the first null-hypothesis was rejected.

Table 3. Pearson Correlation; Self-Esteem with Oral Production

\begin{tabular}{lll}
\hline & & Oral Production \\
\hline \multirow{3}{*}{ Self-Esteem } & Pearson Correlation & $.722^{* *}$ \\
& Sig. (2-tailed) & .000 \\
& $\mathrm{~N}$ & 34 \\
\hline
\end{tabular}

**. Correlation is significant at the 0.01 level (2-tailed).

Null H2) There is not a significant relationship between intermediate EFL students' WTC and their oral production.

A Pearson correlation was run to probe any significant relationship between Intermediate EFL students' level of WTC and their oral production. Based on the results displayed in Table $4(\mathrm{r}(32)=.70, \mathrm{P}<.05$ representing a large effect size) it can be concluded that there was a significant and large correlation between WTC and oral production. Thus the second null-hypothesis was rejected.

Table 4. Pearson Correlation; WTC with Oral Production

\begin{tabular}{lll}
\hline & & Oral Production \\
\hline \multirow{3}{*}{ WTC } & Pearson Correlation & $.708^{* *}$ \\
& Sig. (2-tailed) & .003 \\
& $\mathrm{~N}$ & 32 \\
\hline
\end{tabular}

**. Correlation is significant at the 0.01 level (2-tailed).

Null H3) There is not a significant relationship between oral production of intermediate EFL students and the interaction of self-esteem and WTC.

A one-way ANOVA was run to compare the four groups' means on the oral production in order to probe the third research question. Based on the results displayed in Table 5 it can be concluded that the high self-esteem high WTC (HSHW) showed the highest mean on oral production $(\mathrm{M}=$ $4.43, \mathrm{SD}=.38)$. This was followed by low self-esteem high WTC (LSHW) $(\mathrm{M}=3.25, \mathrm{SD}=.52)$, high self-esteem low WTC (HSLW) $(\mathrm{M}=3.13, \mathrm{SD}=.51)$ and low self-esteem low WTC (LSLW) $(\mathrm{M}=1.83, \mathrm{SD}=.40)$.

Table 5. Descriptive Statistics; Oral Production by Groups

\begin{tabular}{|c|c|c|c|c|c|c|c|c|}
\hline & \multirow{2}{*}{$\mathbf{N}$} & \multirow{2}{*}{ Mean } & \multirow{2}{*}{ Std. Deviation } & \multirow{2}{*}{ Std. Error } & \multicolumn{2}{|c|}{$95 \%$ Confidence Interval for Mean } & \multirow{2}{*}{ Minimum } & \multirow{2}{*}{ Maximum } \\
\hline & & & & & Lower Bound & Upper Bound & & \\
\hline HSHW & 14 & 4.43 & .385 & .103 & 4.21 & 4.65 & 4 & 5 \\
\hline HSLW & 8 & 3.13 & .518 & .183 & 2.69 & 3.56 & 3 & 4 \\
\hline LSHW & 6 & 3.25 & .524 & .214 & 2.70 & 3.80 & 3 & 4 \\
\hline LSLW & 6 & 1.83 & .408 & .167 & 1.40 & 2.26 & 2 & 3 \\
\hline Total & 34 & 3.46 & 1.047 & .180 & 3.09 & 3.82 & 2 & 5 \\
\hline
\end{tabular}

Note. HSHW = high self-esteem and high WTC, HSLW = high self-esteem and low WTC, LSLW = low self-esteem and high WTC and LSLW = low selfesteem and low WTC

The one-way ANOVA results $(\mathrm{F}(3,30)=50.18, \mathrm{P}<.05$, $\omega^{2}=.81$ representing a large effect size) indicated that there were significant differences between the means of the four groups on the oral production. Thus the third nullhypothesis was rejected. 
Table 6. One-Way ANOVA; Oral Production by Groups

\begin{tabular}{llllll}
\hline & Sum of Squares & df & Mean Square & F & Sig. \\
\hline Between Groups & 30.172 & 3 & 10.057 & 50.187 & .000 \\
Within Groups & 6.012 & 30 & .200 & & \\
Total & 36.184 & 33 & & & \\
\hline
\end{tabular}

Although the F-value of 50.18 indicated significant hoc Scheffe's tests (Table 7) should be run to compare the differences between the means of the four groups, the postmeans two by two.

Table 7. Multiple Comparisons

\begin{tabular}{|c|c|c|c|c|c|c|}
\hline \multirow{2}{*}{ (I) Group } & \multirow{2}{*}{ (J) Group } & \multirow{2}{*}{ Mean Difference (I-J) } & \multirow{2}{*}{ Std. Error } & \multirow{2}{*}{ Sig. } & \multicolumn{2}{|c|}{ 95\% Confidence Interval } \\
\hline & & & & & Lower Bound & Upper Bound \\
\hline \multirow{3}{*}{ HSHW } & HSLW & $1.304^{*}$ & .198 & .000 & .72 & 1.89 \\
\hline & LSHW & $1.179^{*}$ & .218 & .000 & .53 & 1.83 \\
\hline & LSLW & $2.595^{*}$ & .218 & .000 & 1.95 & 3.24 \\
\hline HSLW & LSLW & $1.292^{*}$ & .242 & .000 & .58 & 2.01 \\
\hline \multirow{2}{*}{ LSHW } & HSLW & .125 & .242 & .965 & -.59 & .84 \\
\hline & LSLW & $1.417^{*}$ & .258 & .000 & .65 & 2.18 \\
\hline
\end{tabular}

*. The mean difference is significant at the 0.05 level.

Based on the results displayed in Table 6 it can be concluded that:

1) The high self-esteem and high WTC group $(\mathrm{M}=4.43)$ outperformed the high self-esteem and low WTC group (M $=3.13)$ on the oral production $(\mathrm{MD}=1.30, \mathrm{P}<.05)$.

2) The high self-esteem and high WTC group $(\mathrm{M}=4.43)$ outperformed the low self-esteem and high WTC group (M $=3.25)$ on the oral production $(\mathrm{MD}=1.17, \mathrm{P}<.05)$.

3) The high self-esteem and high WTC group $(\mathrm{M}=4.43)$ outperformed the low self-esteem and low WTC group (M $=1.83)$ on the oral production $(\mathrm{MD}=2.59, \mathrm{P}<.05)$.

4) The high self-esteem and low WTC group $(\mathrm{M}=3.13)$ outperformed the low self-esteem and low WTC group (M $=1.83)$ on the oral production $(\mathrm{MD}=1.29, \mathrm{P}<.05)$.

5) There was not any significant difference between the mean scores of the low self-esteem and high WTC group $(\mathrm{M}=3.25)$ and high self-esteem and low WTC group $(\mathrm{M}=$ $3.13)$ on the oral production $(\mathrm{MD}=.125, \mathrm{P}>.05)$.

6) The low self-esteem and high WTC group $(\mathrm{M}=3.25)$ outperformed the low self-esteem and low WTC group (M $=1.83)$ on the oral production $(\mathrm{MD}=1.41, \mathrm{P}<.05)$.

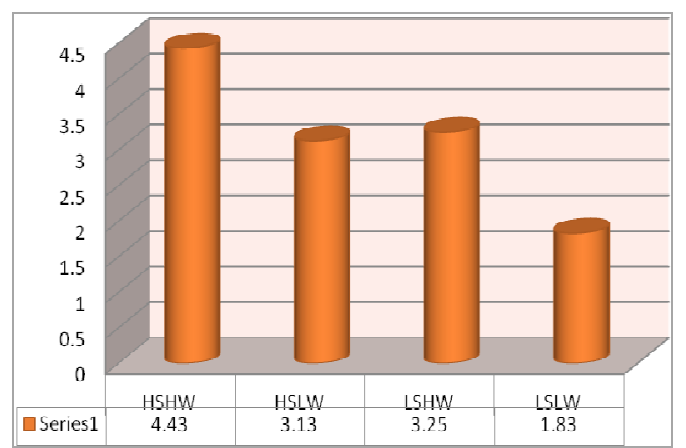

Graph 1. Oral Performance by Groups
As it is obvious, the interaction of both High WTC and High Self-esteem has led to the best performance among all. The lowest record was gained by the Low WTC and Low Self-esteem group. So the higher WTC and the higher selfesteem, the better oral production. The interaction of these two psychological factors empowers students to control and overcome the fear of lecturing.

\section{Discussion and Conclusion}

In this study, as mentioned before, an attempt was made to find answers to the three questions concerning the relationship among the three variables of self-esteem, WTC, and oral production. Appropriate statistical procedures were followed to obtain the required responses for each question. The analysis demonstrated that students with high WTC outperformed the students with low WTC. Both WTC and Self-esteem played an important role in students' oral production. Although, according to Bachman and Palmer (1996) and Çetinkaya (2007), self-esteem is the first and main factor in speaking performance. Therefore, the researchers concluded that WTC could play a principal role as well. High self-esteem alone is not enough for students to deliver satisfactory lectures. In this research, cases with high self-esteem were observed to have problems such as pausing, hemming, panicking, and mumbling while giving their lectures. However, those utilizing the high quality of both WTC and Self-esteem didn't face such difficulties in their performances.

As it is crystal clear, by considering group 1 (high selfesteemed students with high WTC), we can claim that having a high self-esteem in addition to high WTC could guarantee the high quality of oral performances in terms of fluency and accuracy. In sum, it must be emphasized that the interaction of both variables of high self-esteem and high WTC had 
positive effects on lecturing performance of students.

This study was in line with McCroskey and McCroskey's (1986a, 1986b) findings that WTC is positively associated with self-esteem and self-perceived communication competence. In addition, this study proved that as Chan and McCroskey (1987) realized, students with higher scores on the WTC scale were more likely to have more oral production in class than those who scored low on WTC.

This study is also consistent with the Yashima's (2002) findings that there is a direct relationship between WTC and students' attitude toward the international community in the EFL context. This study is also in agreement with Clément's (2003) outcomes that there is a relationship between WTC and students' attitude toward the target language through linguistic self-confidence. This study is in line with Çetinkaya (2007) results that WTC in English in the EFL context is directly related both to attitude toward the international community and perceived linguistic self-confidence.

According to the outcomes of this study, as Yashima, Zenuk-Nishide and Shimizu (2004) claim, students who show willingness to communicate in various contact situations are more inclined to initiate communication in the classroom.

As this research has proved, in accordance with Yashima's (2002) study, students' self-confidence in L2 communicative competence is crucial for their willingness to be involved in L2 communication.

Finally, according to post-hoc Scheffe's test results, it can be asserted that the group which outperformed the others was group one with high self-esteem and high WTC students $(\mathrm{M}=4.43)$. That means the interaction of two variables (self-esteem and WTC) resulted in acceptable lecturing. Therefore, the interaction or joint effect of both high WTC and high self-esteem can have a positive impact on students' oral production.

\section{References}

[1] Alemi, M. (2012). Willingness to communicate in English among Iranian EFL engineering students. TELL, 6 (1), pp. 103-119.

[2] Alemi, M., Daftarifard, P., \& Pashmforoosh, R. (2011). The Impact of language anxiety and language proficiency on WTC in EFL context. Cross- Cultural Communication, 7 (3), 150-166.

[3] Alemi, M., Tajeddin, Z. \& Mesbah, Z. (2013). Willingness to communicate in L2 English: Impact of learner variables. RALS, 4(1), 42-61.

[4] Bachman, L. F. \& Palmer, A. S. (1996). Language testing in practice. Oxford: Oxford University Press.

[5] Çetinkaya B, Y. (2007). Turkish students' willingness to communicate in English. Dokuz Eylül Üniversiy, Висa
Education Faculty Journal, 21, 115-123.

[6] Clément, R., Baker, S. C., \& MacIntyre, P. D. (2003). Willingness to communicate in a second language: The effects of context, norms, and vitality. Journal of Language and Social Psychology, 22(2), 190-209.

[7] Coopersmith, S. (1967). The antecedents of self-esteem. San Francisco: Freeman.

[8] Farhady, H., Jafarpoor, A., \& Birjandi, P. (1998). Testing language skills: from theory to practice. Tehran: SAMT Publications.

[9] MacIntyre, P.D. (2004).Volition and personality: Bringing motivational tendencies to life. Paper presented at the 9th conference of the international association of language and social- psychology, July 1, 2004, Penn State University.

[10] MacIntyre, P. D., Baker, S. C., Cle'ment, R., \&Conrod, S. (2001). Willingness to communicate, social support, and language-learning orientations of immersion students. Studies on Second Language Acquisition, 23, 369-388.

[11] MacIntyre, P., Clement, R., Dornyei, Z., \& Noels, K. (1998). Conceptualizing willingness to communicate in a L2: A situational model of $\mathrm{L} 2$ confidence and affiliation. The Modern Language Journal, 82, 545-562.

[12] Marsh, H.W. (1990). Causal ordering of academic selfconcept and academic achievement: A Multi-wave, longitudinal panel analysis. Journal of Educational Psychology. 82(4), 646-656.

[13] McCroskey, J. C. (1992). Reliability and validity of the willingness to communicate scale. Communication Quarterly, 40, 16-25.

[14] McCroskey, J. C., \& Richmond, V. P. (1987). Willingness to communicate. In J. C. McCroskey \& J. A. Daly (Eds.), Personality and interpersonal communication (pp. 119-131). Newbury Park, CA: Sage.

[15] McCroskey, J. C., \& McCroskey, L. L. (1986a). Correlates of willingness to communicate. Paper presented at the annual convention of the Western Speech Communication Association, Tucson, AZ.

[16] McCroskey, J. C. \& McCroskey, L. L. (1986 b). Self-report as an approach to measuring communication competence. Paper presented at the annual convention of the Central States Speech Association, Cincinnati, OH.

[17] Purkey, W.W. (1970). Self-concept and school achievement. Englewood Cliffs, NJ: Prentice-Hall.

[18] Sorensen, M. J. (2006). Breaking the chain of low selfesteem. New York: Wolf Publishing Company.

[19] Yashima, T. (2002). Willingness to communicate in a second language: The Japanese EFL context. The Modern Language Journal, 86(1), 54-66.

[20] Yashima, T., Zenuk-Nishide, L., \& Shimizu, K. (2004). Influence of attitudes and effect on L2 communication: A study of Japanese high school students. Language Learning, 54(1), 119-152. 